\title{
Evaluation of in Vitro Antioxidant Potential of Carissa Carandas Genotype found in NE India
}

Dipanjali Saikia' ${ }^{1}$ P.J. Handique ${ }^{2}$

'Ph.D Scholar, Department of Biotechnology, Gauhati University, Guwahati, Assam, India ${ }^{2}$ Professor, Department of Biotechnology, Gauhati University, Guwahati, Assam, India

2Corresponding Author: E-mail: pjhandique@rediffmail.com

\section{ABSTRACT}

The present work was designed to study the antioxidant potential of various parts of Carrisa carandas using different assay systems. C. carandas is a semi-wild shrubby plant species found in Assam (India). The species is being used in various traditional medicinal practices in Assam and other parts of NE India. The methanol extract of the fruits of $C$. carandas showed highest radical scavenging activity against DPPH (1, 1diphenyl-2picryl hydrazyl). Ethanol extract of the fruits showed highest radical scavenging activity against $\mathrm{H}_{2} \mathrm{O}_{2}$. The study revealed that the fruits, leaves and seeds extract of $C$. carandas possesses potent antioxidant activity. The antioxidant potential was determined to be in the following order: Fruit $>$ Leaf $>$ Seed extracts.

Keywords: Carissa Carandas, Antioxidant,Radical Scavenging, DPPH, Reducing Power.

\section{INTRODUCTION}

Plants are well known source of biologically active natural products with potent therapeutic value. Phytoconstituents such as carotenoids, tocopherols and polyphenols possess considerable antioxidant capacity. It is known that reactive oxygen species (ROS) play a crucial role in the development of various ailments such as arthritis, asthma, dementia, carcinoma and several others. Moreover, the excess production of active oxygen species like $\mathrm{O}_{2}, \mathrm{H}_{2} \mathrm{O}_{2}$ and $\mathrm{OH}$ - may lead to tissue injury, DNA damage, thiol oxidation and lipid peroxidation, cardiac disorder, chronic gut inflammation, cancer and AIDS in humans [1]. However, free radicals play a positive role in phagocytosis, energy production and regulation of cell growth. But free radicals produced in the body react with various biological molecules namely lipids, proteins and deoxyribonucleic acids resulting in oxidative stress [1], [2], [3], [4]. Oxidative stress is commonly defined as a disturbance in the prooxidant and antioxidant balance. Although human body is protected by natural antioxidant defense, there is always a demand for antioxidants from plant sources. Therefore, identification of antioxidant rich plant resources and evaluation of their antioxidant potential is considered as a high priority area of research.

C. carandas $\mathrm{L}$. is a $3-5 \mathrm{~m}$ tall evergreen shrub or climbing tree with strong thorns in pairs (Figure 1). The species has been found in semi-wild situation in home gardens in several places of Assam and other parts of North East India [5]. "Semi-wild" applies to those plants that are indigenous and naturalized to the region while nurtured also through maintenance or acceptance by people in their crop fields and home gardens [6]. Stem is fresh green, cylindrical in shape, smooth on surface, $4-5 \mathrm{~cm}$ internodes. The branches are set with sharp simple or forked thorns in pairs in the axils of the leaves, $2-4 \mathrm{~cm}$ long and are usually alternate, numerous and spreading, forming dense masses; branches are usually without spines. Bark is smooth light grey or yellowish brown [7]. Leaves are simple, evergreen, opposite [8]. Flowers are white, 
often tinged with pale-pink coloured, found in groups, scarcely odorous. Fruits have fairly thin but tough peel. Peel and pulp are usually green and pinkish white when immature but turns purplish- red to darkpurple and shiny when ripened depending on the genotype. Ripe fruits are sweet and edible. Unripe ones are sour and pickled. Various parts of $C$. carandas have been used in many ethno-medicines as stated in several published work [9], [10], [11], [12], [13]. Roots are used as stomachic and anthelmintic in traditional medicinal practices of Assam. Decoction of leaves is given in the treatment of remittent fever [5]. However scientific validation of the medicinal information for the $C$. carandas genotype found in Assam is obscure. Considering the medicinal importance, the objectives of this study was designed to evaluate the antioxidant potential of various parts viz., fruit, leaf and seed of Carissa carandas using DPPH (1,1diphenyl-2-picryl hydrazyl) and hydrogen peroxide $\left(\mathrm{H}_{2} \mathrm{O}_{2}\right)$ radical scavenging methods.

\section{METHODS AND MATERIAL}

Plant samples were collected from a semi-wild population of $C$. carandas found in a local Garden in Nagaon district of Assam, India. The fresh leaves, fruits and seeds were gathered during the month of June to August, 2018. The specimen was identified in the Department of Botany, Gauhati University, Assam, India. All the chemicals and solvents were of analytical grade obtained from Hi-Media Laboratories Pvt. Ltd., Mumbai. A UV-visible spectrophotometer (Thermo Fischer scientific) was used for recording the spectra.

The collected samples were cleaned and washed thoroughly using tap water followed by distilled water. The ripened fruits were sliced into small pieces to increase the surface area; seeds were removed and then dried under shade for 7 days. Dried samples were then ground to produce fine homogenous powder using a grinder. The powdered samples were preserved in clean plastic containers away from light, heat and moisture until use. For preparation of cold extracts, $10 \mathrm{~g}$ of each powdered plant sample (leaf, fruit and seed) soaked in $100 \mathrm{~mL}$ of selected solvents viz., Ethanol, Acetone, Methanol, Ethyl Acetate, Diethyl ether, petroleum ether, Chloroform and Distilled water at room temperature. Each sample was filtered using Whatman no.1 filter paper and the filtered solutions were evaporated to dryness using water bath at $40^{\circ} \mathrm{C}$ for overnight. The plant extracts were then stored at $4^{\circ} \mathrm{C}$ for further analysis. Chemical analysis was done to estimate antioxidant activity of the samples.

The antioxidant activity of 8 different extracts (methanol, ethanol, acetone, chloroform, petroleum ether, distilled water, ethyl acetate and diethyl ether) of $C$. carandas plant material was assayed. The extracts were tested for their radical scavenging ability against DPPH as per method described by Blois [14]. The scavenging activity of the extracts on hydroxyl radical was measured according to a method earlier described by Ruch [15] and Yu et al. [16]. Reducing Power Assay was carried out as per the method described by Yildrin [17].

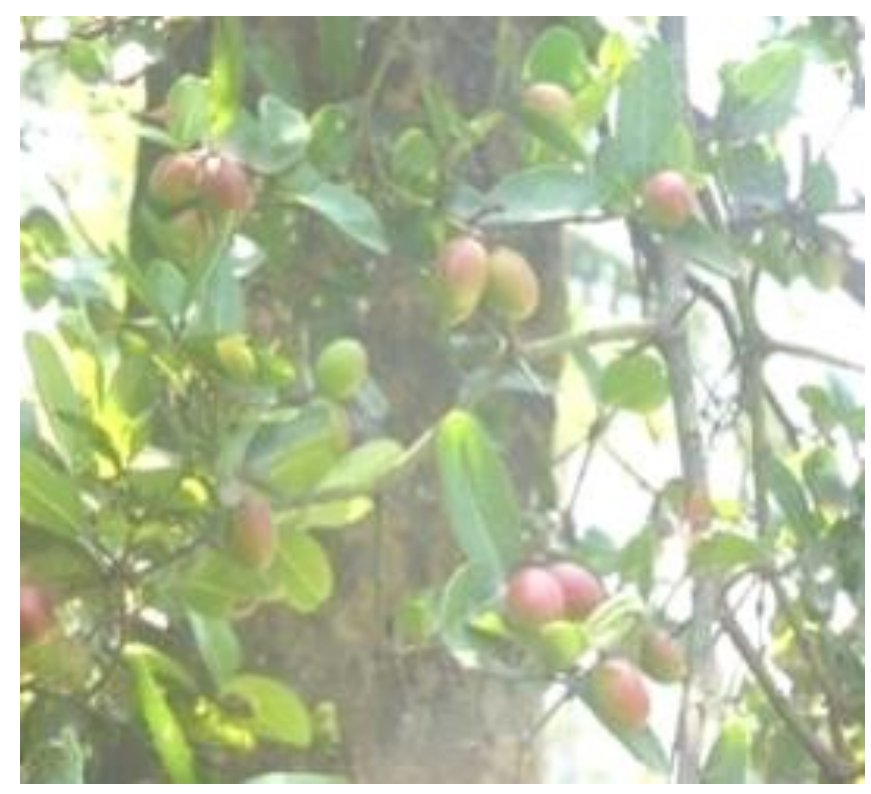

Figure 1: A fruiting twig of Carissa carandas found in Assam (India) 


\section{DPPH Scavenging Assay}

Stock solutions of all the extracts of different plant parts with the concentration of $1000 \mu \mathrm{g} / \mathrm{ml}$ were prepared by dissolving $20 \mathrm{mg}$ of the extract separately in eight number of different solvents (Ethanol, Acetone, Methanol, Ethyl Acetate, Diethyl ether, petroleum ether, Chloroform and Distilled water) and the final volume was made up to $20 \mathrm{ml}$. The stock was diluted to various concentrations like $10 \mu \mathrm{g} / \mathrm{ml}$, $20 \mu \mathrm{g} / \mathrm{ml}, 40 \mu \mathrm{g} / \mathrm{ml}, 80 \mu \mathrm{g} / \mathrm{ml}$ and $160 \mu \mathrm{g} / \mathrm{ml}$ solutions with each solvent earlier used for extraction. The total volume was made $1 \mathrm{ml}$ in all the test tubes and to this $2 \mathrm{ml}$ of solvent solution of DPPH was added thereby making the final volume to $3 \mathrm{ml}$. The test tubes were incubated at $37^{\circ} \mathrm{C}$ for 30 minutes. Optical densities of these samples were measured for degree of discoloration from purple to yellow at $517 \mathrm{~nm}$ along with blank. Each of the above mentioned eight solvents with respective plant extracts served as blank. Ascorbic acid was used as a standard. Lower absorbance of the reaction mixture indicated higher free radical scavenging activity.

The DPPH radical scavenging activity of the plant extracts were calculated by the following equation:

\section{$\%$ inhabitation $=\left[\mathrm{A}_{0}-\mathrm{A}_{\mathrm{s}}\right] / \mathrm{A}_{0} \times 100$ \\ Where, \\ $\mathrm{A}_{0}=$ Absorbance of DPPH (unreduced) \\ As $=$ Absorbance of the sample and standard}

The percentage scavenging activity of each extract was compared with L-Ascorbic acid, the positive control. IC50 is defined as the concentration of antioxidant that causes $50 \%$ loss of the initial DPPH free radical concentration (color). IC50 of reference antioxidant compound i.e. ascorbic acid was used for comparison to IC50 of the extracts. The least value of IC50 represents the better antioxidant and high value for antioxidant activity. IC50 value of each extract was determined from the plotted graph of percentage DPPH neutralization versus concentration of extract.

\section{Statistical Analysis}

The data were subjected to statistical analysis by Origin ver. 6.1. All the assays were recorded in triplicates and the values were expressed as mean \pm S.D. Each measurements were significantly different at $\mathrm{p}<0.05$.

\section{Hydrogen Peroxide Scavenging Assay}

Hydrogen peroxide $(40 \mathrm{mM})$ was prepared in phosphate buffer $(50 \mathrm{mM} \quad \mathrm{pH}$ 7.4). Different concentration of the plant extracts $(10 \mu \mathrm{g} / \mathrm{ml}$ to 160 $\mu \mathrm{g} / \mathrm{ml})$ was added to $600 \mu \mathrm{l}$ of $\mathrm{H}_{2} \mathrm{O}_{2}(0.6 \mathrm{ml}, 40 \mathrm{mM})$ and the final volume was made $3 \mathrm{ml}$ with distilled water. The concentration of hydrogen peroxide was determined by absorption at $230 \mathrm{~nm}$ after $10 \mathrm{~min}$ against a blank solution containing phosphate buffer without hydrogen peroxide. Ascorbic acid was taken as standard. The percentage of hydrogen peroxide scavenging of both the extracts and standard compounds was calculated as in the case of DPPH.

$$
\% \text { inhabitation }=\left[\mathrm{A}_{0}-\mathrm{A}_{s}\right] / \mathrm{A}_{0} \times 100
$$

Where,

$\mathrm{A}_{0^{-}}=$Absorbance of $\mathrm{H}_{2} \mathrm{O}_{2}$ (unreduced)

As- = Absorbance of the sample and standard

Hydrogen peroxide produces hydroxyl radicals in cells. Scavenging of these radicals by the test extract is used as a test for antioxidant activity. The reduction of these radicals is seen by the decreased absorbance at $230 \mathrm{~nm}$ with increasing concentration of the test extract. The mean percentage $\mathrm{H}_{2} \mathrm{O}_{2}$ inhibition values were plotted against concentration.

\section{Reducing Power Assay}

Substances having the reducing potential react with potassium ferricyanide $\left(\mathrm{Fe}^{3}{ }^{*}\right)$ to potassium ferro cyanide $\left(\mathrm{Fe}^{2}{ }_{+}\right)$which then further react with ferric chloride to form a Ferric -Ferrous complex which has an absorbance maximum at $700 \mathrm{~nm}$. Phosphate buffer was prepared by mixing Dibasic Sodium Phosphate $(37.50 \mathrm{ml}$ of $0.2 \mathrm{M})$ with $62.5 \mathrm{ml}$ of monobasic sodium 
phosphate and diluted to $100 \mathrm{ml}$ with distilled water. Different concentration of the plant extracts $(10 \mu \mathrm{g} / \mathrm{ml}-160 \mu \mathrm{g} / \mathrm{ml})$ were mixed with $2.5 \mathrm{ml}$ of phosphate buffer (pH6.6) and $2.5 \mathrm{ml}$ of $10 \mathrm{~g} / 1$ (1\%) potassium ferricyanide. The mixture was incubated at $50^{\circ} \mathrm{C}$ for 30 minutes and an aliquot $(2.5 \mathrm{ml})$ of $10 \%$ of trichloroacetic acid was added to the mixture which was then centrifuged at $3000 \mathrm{rpm}$ for 10minutes. Finally $2.5 \mathrm{ml}$ of the upper layer was mixed with $2.5 \mathrm{~m}$ of distilled water and $0.5 \mathrm{ml}$ of $1 \mathrm{~g} / 1(0.1 \%)$ ferric chloride. The absorbance of resulting solution was measured at $700 \mathrm{~nm}$ by using a UV-visible spectrophotometer. Water was used as blank while LAscorbic acid was used as standard. Increasing absorbance of the reaction mixture indicates increase in reducing power assay. Reducing power of each extract was estimated from the plotted graph of percentage reducing power versus concentration of extract.

\section{III.RESULTS AND DISCUSSION}

\section{DPPH Radical scavenging assay}

The fruit extracts exhibited a potent free radical scavenging activity. The inhibition percentage of methanol extract of fruit showed highest radical scavenging activity gradually increasing from $28.37 \%$ to $91.22 \%$ at $10 \mu \mathrm{g} / \mathrm{ml}-160 \mu \mathrm{g} / \mathrm{ml}$. Ethyl acetate extract showed less activity compared to ethanol, chloroform, acetone, water, diethyl ether and petroleum ether extracts respectively (Table1; Figure 2). Methanol and ethanol extracts of fruit showed $50 \%$ and above inhibition at $40 \mu \mathrm{g} / \mathrm{ml}$. fruits extracts in chloroform, water, acetone and petroleum ether showed at $80 \mu \mathrm{g} / \mathrm{ml}$ while diethyl ether at $160 \mu \mathrm{g} / \mathrm{ml}$ and ethyl acetate showed above $160 \mu \mathrm{g} / \mathrm{ml}$. The extracts showed significant influence when compared to ascorbic acid. The leaf extracts exhibited radical scavenging activity against DPPH. The inhibition percentage of leaf methanol extract showed $28.37 \%$ to $80.79 \%$ at $10 \mu \mathrm{g} / \mathrm{ml}-160 \mu \mathrm{g} / \mathrm{ml}$ while petroleum ether showed less scavenging activity compared to ethanol, chloroform, acetone, water, diethyl ether and ethyl acetate respectively (Table 2; Figure 3). Methanol, ethanol, chloroform and acetone extracts of leaf showed $50 \%$ and above inhibition at $40 \mu \mathrm{g} / \mathrm{ml}$ and water showed at $80 \mu \mathrm{g} / \mathrm{ml}$ while diethyl ether and petroleum ether at $160 \mu \mathrm{g} / \mathrm{ml}$ and ethyl acetate showed above $160 \mu \mathrm{g} / \mathrm{ml}$. The leaf extracts showed less significant scavenging activity compared to fruit extract. The inhibition \% of seed extracts increased with increasing the concentration. The inhibition percentage of seed methanol extract showed $28.94 \%$ to $78.05 \%$ at 10 $160 \mu \mathrm{g} / \mathrm{ml}$ while petroleum ether showed less scavenging activity compared to chloroform, ethanol, acetone, water, ethyl acetate and diethyl ether respectively (Table 3; Figure 4 ). The seed methanol extract showed $50 \%$ and above inhibition at $20 \mu \mathrm{g} / \mathrm{ml}$ while chloroform and ethanol extract showed at $40 \mu \mathrm{g} / \mathrm{ml}$. Acetone showed at $80 \mu \mathrm{g} / \mathrm{ml}$ while water, ethyl acetate and diethyl ether at $160 \mu \mathrm{g} / \mathrm{ml}$ and petroleum ether showed above $160 \mu \mathrm{g} / \mathrm{ml}$.

\section{$\mathrm{H}_{2} \mathrm{O}_{2}$ Radical scavenging assay}

The inhibition $\%$ of Fruit extracts against $\mathrm{H}_{2} \mathrm{O}_{2}$ exhibited a strong free radical scavenging activity. The inhibition percentage of fruit ethanol extract showed $55.80 \%$ to $88.73 \%$ at $10 \mu \mathrm{g} / \mathrm{ml}-160 \mu \mathrm{g} / \mathrm{ml}$ while petroleum ether showed less scavenging activity compared to the extracts in chloroform, methanol, acetone, water, ethyl acetate and diethyl ether respectively (Table 4; Figure 5). The fruit ethanol extract showed $50 \%$ and above inhibition at $20 \mu \mathrm{g} / \mathrm{ml}$ while chloroform at $40 \mu \mathrm{g} / \mathrm{ml}$. Methanol extract showed at $10 \mu \mathrm{g} / \mathrm{ml}$, acetone and water at $80 \mu \mathrm{g} / \mathrm{ml}$, ethyl acetate at $160 \mu \mathrm{g} / \mathrm{ml}$ and, diethyl ether and petroleum ether showed above $160 \mu \mathrm{g} / \mathrm{ml}$ concentration. The inhibition \% of leaf extracts increased with increase in the concentration. The inhibition percentage of leaf ethanol extract showed $45.95 \%$ to $96.02 \%$ at $10 \mu \mathrm{g} / \mathrm{ml}-160 \mu \mathrm{g} / \mathrm{ml}$ while ethyl acetate showed less scavenging activity compared to chloroform, water, methanol, acetone, petroleum ether and diethyl ether respectively (Table 5, Figure 6). 
Ethanol and chloroform extract of leaf showed 50\% and above inhibition at $20 \mu \mathrm{g} / \mathrm{ml}$. Water extract of leaf showed activity at $40 \mu \mathrm{g} / \mathrm{ml}$, methanol and acetone extracts showed at $80 \mu \mathrm{g} / \mathrm{ml}$ while petroleum ether and diethyl ether showed activity at $160 \mu \mathrm{g} / \mathrm{ml}$. The leaf extracts showed significant influence when compared to ascorbic acid. The seed extracts exhibit radical scavenging activity against $\mathrm{H}_{2} \mathrm{O}_{2}$. The inhibition percentage of seed ethanol extract showed $45.75 \%$ to $92.11 \%$ at $10 \mu \mathrm{g} / \mathrm{ml}-160 \mu \mathrm{g} / \mathrm{ml}$ while diethyl ether showed less scavenging activity compared to methanol, chloroform, water, acetone, petroleum ether and ethyl acetate respectively (Table 6 , Figure 7 ). The seed ethanol extract showed $50 \%$ and above inhibition at $20 \mu \mathrm{g} / \mathrm{ml}$, methanol and chloroform showed at $40 \mu \mathrm{g} / \mathrm{ml}$ while water, acetone, petroleum ether showed at $160 \mu \mathrm{g} / \mathrm{ml}$ and diethyl ether and ethyl acetate at above $160 \mu \mathrm{g} / \mathrm{ml}$. The seed extracts showed less significant scavenging activity compared to fruit and leaf extracts.

\section{Reducing power assay}

The fruit extracts showed an increase in reducing power with increase in the concentration. The fruit methanol extract showed 0.188 to 1.915 at $10 \mu \mathrm{g} / \mathrm{ml}$ $160 \mu \mathrm{g} / \mathrm{ml}$ while petroleum ether showed less reducing power compared to ethanol, chloroform, acetone, water, diethyl ether and ethyl acetate (Table 7, Figure 8). The leaf methanol extract showed 0.167 to 1.574 at $10 \mu \mathrm{g} / \mathrm{ml}-160 \mu \mathrm{g} / \mathrm{ml}$ while petroleum ether showed less reducing power compared to chloroform, ethanol, acetone, water, ethyl acetate and diethyl ether (Table 8, Figure 9).The seed ethanol extract showed increasing reducing power gradually from 0.141 to 1.265 at $10 \mu \mathrm{g} / \mathrm{ml}-160 \mu \mathrm{g} / \mathrm{ml}$ while ethyl acetate showed less reducing power compared to methanol, acetone, chloroform, water, diethyl ether and petroleum ether (Table 9, Figure 10).

Table 1: \%inhibition concentration for DPPH radical scavenging activity of Fruit extracts of Carissa carandas L.

\begin{tabular}{|c|c|c|c|c|c|c|c|c|c|c|}
\hline \multirow{2}{*}{$\begin{array}{l}\text { Sl. } \\
\text { No. }\end{array}$} & \multirow{2}{*}{$\begin{array}{l}\text { Conc. } \\
(\mu \mathrm{g} / \\
\mathrm{ml})\end{array}$} & \multicolumn{9}{|c|}{ \%inhibition } \\
\hline & & $\begin{array}{l}\text { ascorbic } \\
\text { acid }\end{array}$ & methanol & ethanol & chloroform & acetone & water & $\begin{array}{l}\text { diethyl } \\
\text { ether }\end{array}$ & $\begin{array}{l}\text { petroleum } \\
\text { ether }\end{array}$ & $\begin{array}{l}\text { ethyl } \\
\text { acetate }\end{array}$ \\
\hline 1 & 10 & $19.91 \pm 0.11$ & $28.37 \pm 0.29$ & $27.42 \pm 0.11$ & $21.25 \pm 0.11$ & $16.60 \pm 0.19$ & $14.31 \pm 0.19$ & $12.79 \pm 0.19$ & $10.31 \pm 0.33$ & $5.53 \pm 0.19$ \\
\hline 2 & 20 & $25.05 \pm 0.89$ & $38.04 \pm 0.11$ & $32.25 \pm 0.19$ & $37.79 \pm 0.19$ & $20.68 \pm 0.11$ & $38.17 \pm 0.19$ & $23.35 \pm 0.11$ & $21.57 \pm 0.19$ & $11.13 \pm 0.29$ \\
\hline 3 & 40 & $28.90 \pm 0.76$ & $76.97 \pm 0.11$ & $54.01 \pm 0.19$ & $48.15 \pm 0.11$ & $40.49 \pm 0.19$ & $40.49 \pm 0.19$ & $28.18 \pm 0.29$ & $28.37 \pm 0.29$ & $20.99 \pm 0.19$ \\
\hline 4 & 80 & $32.87 \pm 0.74$ & $80.85 \pm 0.11$ & $75.19 \pm 0.19$ & $77.67 \pm 0.19$ & $51.85 \pm 0.22$ & $67.94 \pm 0.19$ & $49.55 \pm 0.11$ & $53.50 \pm 0.11$ & $25.83 \pm 0.11$ \\
\hline 5 & 160 & $42.07 \pm 0.91$ & $91.22 \pm 0.29$ & $90.52 \pm 0.11$ & $85.31 \pm 0.19$ & $79.96 \pm 0.19$ & $75.76 \pm 0.19$ & $64.38 \pm 0.11$ & $56.11 \pm 0.42$ & $49.68 \pm 0.11$ \\
\hline
\end{tabular}

${ }^{*}$ Data are mean of triplicate measurements \pm standard deviation. Each measurement were significantly different at $\mathrm{p}<0.05$.

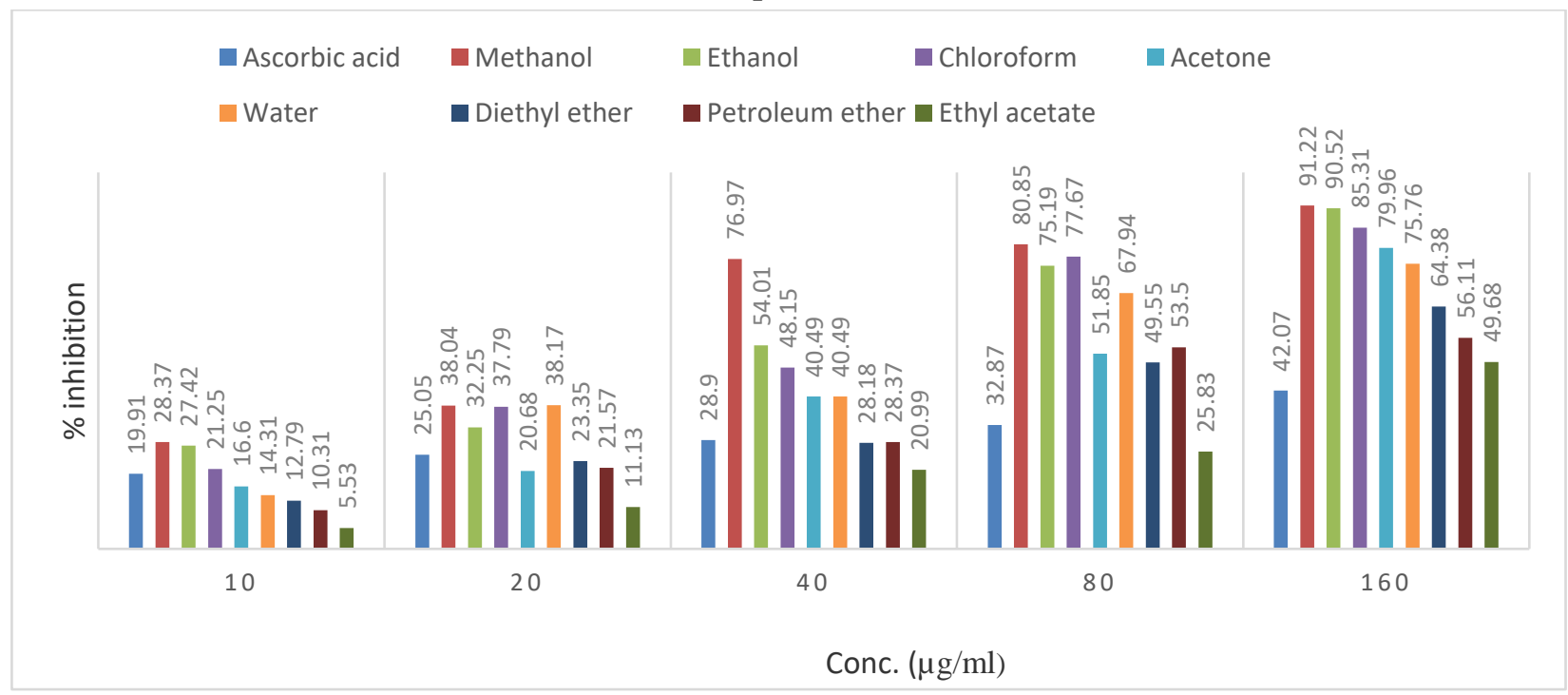

Figure 2: DPPH scavenging activity of Fruit extracts of Carissa carandas L. 
Table 2: \% inhibition concentration for DPPH radical scavenging activity of Leaf extracts of Carissa carandas

\begin{tabular}{|c|c|c|c|c|c|c|c|c|c|c|}
\hline \multirow{2}{*}{$\begin{array}{l}\text { Sl. } \\
\text { No }\end{array}$} & \multirow{2}{*}{$\begin{array}{l}\text { Conc. } \\
(\mu \mathrm{g} / \mathrm{m} \\
\text { 1) }\end{array}$} & \multicolumn{9}{|c|}{ \%inhibition } \\
\hline & & $\begin{array}{l}\text { ascorbic } \\
\text { acid }\end{array}$ & methanol & ethanol & chloroform & acetone & water & diethyl ether & $\begin{array}{l}\text { petroleum } \\
\text { ether }\end{array}$ & $\begin{array}{l}\text { ethyl } \\
\text { acetate }\end{array}$ \\
\hline 1 & 10 & $19.91 \pm 0.11$ & $28.37 \pm 0.29$ & $25.83 \pm 0.11$ & $20.48 \pm 0.11$ & $16.60 \pm 0.19$ & $14.76 \pm 0.61$ & $11.13 \pm 0.29$ & $10.43 \pm 0.11$ & $8.52 \pm 0.11$ \\
\hline 2 & 20 & $25.05 \pm 0.89$ & $43.38 \pm 0.58$ & $49.55 \pm 0.11$ & $38.17 \pm 0.19$ & $37.47 \pm 0.11$ & $29.14 \pm 0.19$ & $28.44 \pm 0.19$ & $27.42 \pm 0.11$ & $18.70 \pm 0.19$ \\
\hline 3 & 40 & $28.90 \pm 0.76$ & $51.21 \pm 0.29$ & $56.30 \pm 0.19$ & $52.16 \pm 0.11$ & $59.22 \pm 0.11$ & $43.38 \pm 0.58$ & $33.97 \pm 0.19$ & $30.60 \pm 0.11$ & $30.47 \pm 0.11$ \\
\hline 4 & 80 & $32.87 \pm 0.74$ & $71.18 \pm 0.19$ & $69.21 \pm 0.11$ & $69.66 \pm 0.19$ & $49.68 \pm 0.11$ & $58.91 \pm 0.22$ & $43.70 \pm 0.19$ & $44.34 \pm 0.29$ & $38.42 \pm 0.29$ \\
\hline 5 & 160 & $42.07 \pm 0.91$ & $80.79 \pm 0.11$ & $79.58 \pm 0.19$ & $78.82 \pm 0.19$ & $76.91 \pm 0.19$ & $63.10 \pm 0.11$ & $59.73 \pm 0.19$ & $56.81 \pm 0.11$ & $48.16 \pm 0.11$ \\
\hline
\end{tabular}

${ }^{*}$ Data are mean of triplicate measurements \pm standard deviation. Each measurement were significantly different at $\mathrm{p}<0.05$.

Table 3: \% inhibition concentration for DPPH radical scavenging activity of Seed extracts of Carissa carandas

\begin{tabular}{|c|c|c|c|c|c|c|c|c|c|c|}
\hline \multirow{2}{*}{$\begin{array}{l}\text { Sl. } \\
\text { No }\end{array}$} & \multirow{2}{*}{$\begin{array}{l}\text { Conc. } \\
(\mu \mathrm{g} / \mathrm{m} \\
\text { l) }\end{array}$} & \multicolumn{9}{|c|}{ \%inhibition } \\
\hline & & $\begin{array}{l}\text { ascorbic } \\
\text { acid }\end{array}$ & methanol & ethanol & chloroform & acetone & water & $\begin{array}{l}\text { diethyl } \\
\text { ether }\end{array}$ & $\begin{array}{l}\text { petroleum } \\
\text { ether }\end{array}$ & $\begin{array}{l}\text { ethyl } \\
\text { acetate }\end{array}$ \\
\hline 1 & 10 & $19.91 \pm 0.11$ & $28.94 \pm 0.29$ & $21.37 \pm 0.19$ & $23.41 \pm 0.11$ & $19.66 \pm 0.19$ & $18.70 \pm 0.19$ & $8.46 \pm 0.11$ & $6.87 \pm 0.19$ & $10.37 \pm 0.11$ \\
\hline 2 & 20 & $25.05 \pm 0.89$ & $58.84 \pm 0.29$ & $48.60 \pm 0.72$ & $49.11 \pm 0.72$ & $38.23 \pm 0.22$ & $38.17 \pm 0.19$ & $21.37 \pm 0.19$ & $12.85 \pm 0.11$ & $21.12 \pm 0.29$ \\
\hline 3 & 40 & $28.90 \pm 0.76$ & $63.10 \pm 0.58$ & $55.53 \pm 0.19$ & $58.27 \pm 1.23$ & $44.95 \pm 0.19$ & $44.53 \pm 0.22$ & $37.85 \pm 0.22$ & $38.23 \pm 0.22$ & $37.98 \pm 0.38$ \\
\hline 4 & 80 & $32.87 \pm 0.74$ & $71.76 \pm 0.38$ & $68.34 \pm 0.94$ & $64.70 \pm 0.19$ & $65.39 \pm 0.11$ & $49.62 \pm 0.19$ & $43.64 \pm 0.22$ & $38.97 \pm 0.19$ & $48.16 \pm 0.11$ \\
\hline 5 & 160 & $42.07 \pm 0.91$ & $78.05 \pm 0.19$ & $71.76 \pm 1.16$ & $76.15 \pm 0.19$ & $68.64 \pm 0.29$ & $63.04 \pm 0.11$ & $56.49 \pm 0.19$ & $44.21 \pm 0.11$ & $59.73 \pm 0.19$ \\
\hline
\end{tabular}

${ }^{*}$ Data are mean of triplicate measurements \pm standard deviation. Each measurement were significantly different at $\mathrm{p}<0.05$.

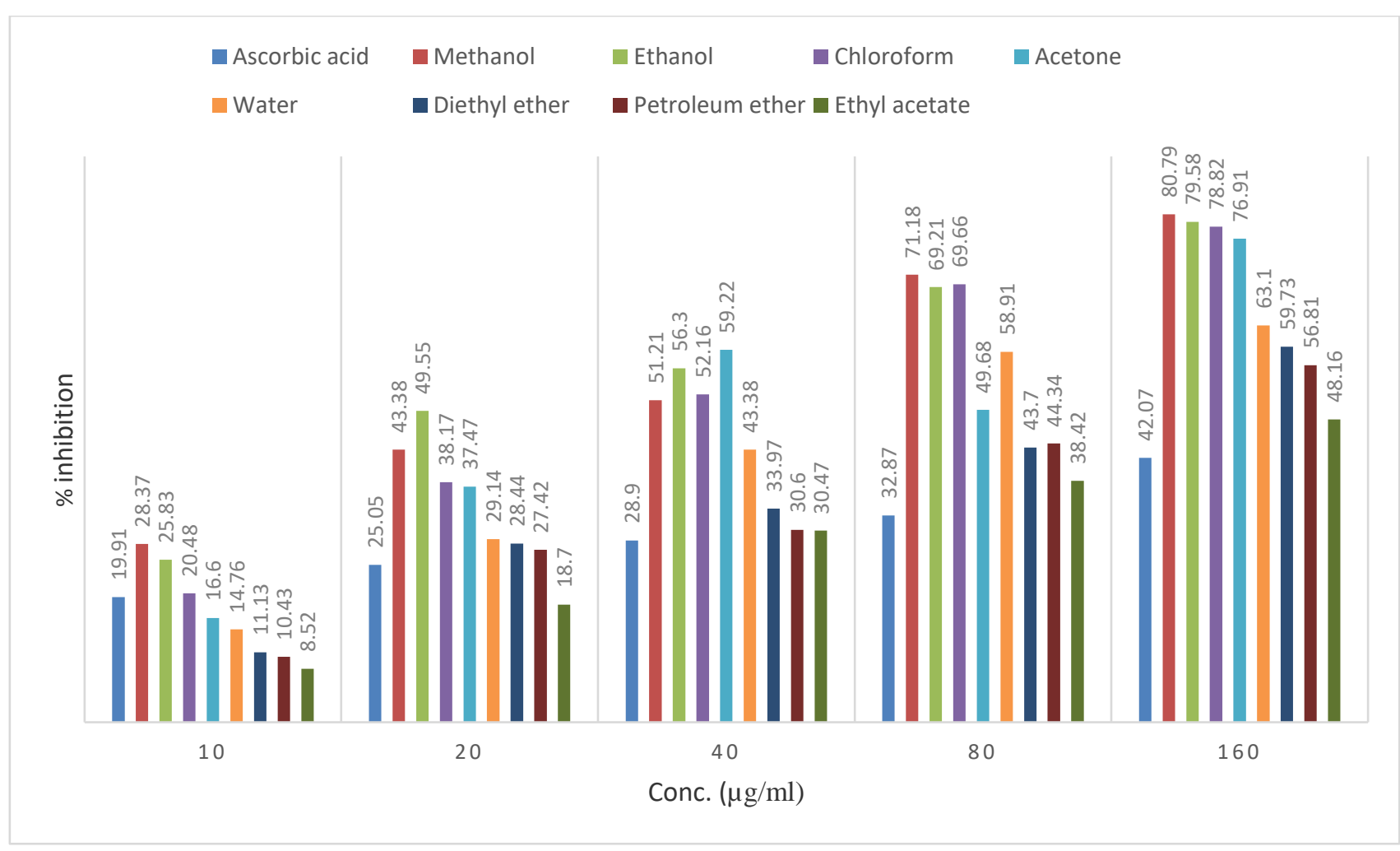

Figure 3: DPPH scavenging activity of Leaf extracts of Carissa carandas L 
Table 4: \% inhibition concentration for $\mathrm{H}_{2} \mathrm{O}_{2}$ radical scavenging activity of Fruit extracts of Carissa carandas

\begin{tabular}{|c|c|c|c|c|c|c|c|c|c|c|}
\hline \multirow{2}{*}{$\begin{array}{l}\text { Sl. } \\
\text { No }\end{array}$} & \multirow{2}{*}{$\begin{array}{l}\text { Conc. } \\
(\mu \mathrm{g} / \mathrm{m} \\
1)\end{array}$} & \multicolumn{9}{|c|}{ \%inhibition } \\
\hline & & $\begin{array}{l}\text { ascorbic } \\
\text { acid }\end{array}$ & methanol & ethanol & chloroform & acetone & water & $\begin{array}{l}\text { diethyl } \\
\text { ether }\end{array}$ & $\begin{array}{l}\text { petroleum } \\
\text { ether }\end{array}$ & $\begin{array}{l}\text { ethyl } \\
\text { acetate }\end{array}$ \\
\hline 1 & 10 & $10.79 \pm 0.20$ & $55.80 \pm 0.12$ & $48.38 \pm 0.20$ & $39.88 \pm 0.20$ & $20.85 \pm 0.20$ & $16.80 \pm 0.20$ & $11.07 \pm 0.12$ & $5.40 \pm 0.23$ & $12.96 \pm 0.20$ \\
\hline 2 & 20 & $27.47 \pm 0.20$ & $60.53 \pm 0.20$ & $63.56 \pm 0.41$ & $49.80 \pm 0.20$ & $30.77 \pm 0.20$ & $28.14 \pm 0.20$ & $21.26 \pm 0.20$ & $8.64 \pm 0.23$ & $26.92 \pm 0.20$ \\
\hline 3 & 40 & $36.47 \pm 0.47$ & $68.22 \pm 0.20$ & $74.97 \pm 0.12$ & $52.43 \pm 0.20$ & $49.06 \pm 0.31$ & $47.17 \pm 0.20$ & $33.60 \pm 0.20$ & $9.72 \pm 0.20$ & $31.16 \pm 0.02$ \\
\hline 4 & 80 & $53.36 \pm 0.59$ & $80.36 \pm 0.20$ & $91.36 \pm 0.31$ & $79.76 \pm 0.20$ & $67.41 \pm 0.20$ & $55.67 \pm 0.20$ & $42.11 \pm 0.20$ & $25.37 \pm 0.12$ & $45.95 \pm 0.20$ \\
\hline 5 & 160 & $54.5 \pm 0.45$ & $88.73 \pm 0.42$ & $92.31 \pm 0.20$ & $87.65 \pm 0.20$ & $74.29 \pm 0.20$ & $93.52 \pm 0.12$ & $46.09 \pm 0.31$ & $35.83 \pm 0.20$ & $80.84 \pm 0.20$ \\
\hline
\end{tabular}

*Data are mean of triplicate measurements \pm standard deviation. Each measurement were significantly different at $\mathrm{p}<0.05$.

Table 5: \% inhibitionconcentration for $\mathrm{H}_{2} \mathrm{O}_{2}$ radical scavenging activity of Leaf extracts of Carissa carandas $\mathrm{L}$.

\begin{tabular}{|c|c|c|c|c|c|c|c|c|c|c|}
\hline \multirow{2}{*}{$\begin{array}{l}\text { Sl. } \\
\text { No }\end{array}$} & \multirow{2}{*}{$\begin{array}{l}\text { Conc. } \\
(\mu \mathrm{g} / \mathrm{m} \\
\text { l) }\end{array}$} & \multicolumn{9}{|c|}{ \%inhibition } \\
\hline & & $\begin{array}{l}\text { ascorbic } \\
\text { acid }\end{array}$ & methanol & ethanol & chloroform & acetone & water & $\begin{array}{l}\text { diethyl } \\
\text { ether }\end{array}$ & $\begin{array}{c}\text { petroleum } \\
\text { ether }\end{array}$ & $\begin{array}{l}\text { ethyl } \\
\text { acetate }\end{array}$ \\
\hline 1 & 10 & $10.79 \pm 0.20$ & $20.99 \pm 0.12$ & $45.95 \pm 0.20$ & $39.68 \pm 0.20$ & $20.65 \pm 0.20$ & $32.19 \pm 0.20$ & $5.47 \pm 0.20$ & $14.17 \pm 0.20$ & $8.77 \pm 0.23$ \\
\hline 2 & 20 & $27.47 \pm 0.20$ & $21.05 \pm 0.20$ & $62.82 \pm 0.31$ & $58.30 \pm 0.20$ & $21.12 \pm 0.12$ & $46.15 \pm 0.20$ & $8.70 \pm 0.20$ & $28.07 \pm 0.23$ & $11.10 \pm 0.12$ \\
\hline 3 & 40 & $36.47 \pm 0.47$ & $42.71 \pm 0.20$ & $85.83 \pm 0.41$ & $80.77 \pm 0.20$ & $41.70 \pm 0.20$ & $68.15 \pm 0.12$ & $17.21 \pm 0.20$ & $46.49 \pm 0.42$ & $27.80 \pm 0.62$ \\
\hline 4 & 80 & $53.36 \pm 0.59$ & $60.12 \pm 0.20$ & $92.11 \pm 0.20$ & $91.50 \pm 0.20$ & $62.75 \pm 0.20$ & $87.65 \pm 0.20$ & $31.98 \pm 0.20$ & $48.58 \pm 0.20$ & $33.60 \pm 0.20$ \\
\hline 5 & 160 & $54.5 \pm 0.45$ & $89.27 \pm 0.20$ & $96.02 \pm 0.31$ & $92.11 \pm 0.20$ & $89.34 \pm 0.42$ & $90.49 \pm 0.20$ & $57.29 \pm 0.20$ & $70.38 \pm 0.31$ & $45.69 \pm 0.31$ \\
\hline
\end{tabular}

${ }^{*}$ Data are mean of triplicate measurements \pm standard deviation. Each measurement were significantly different at $\mathrm{p}<0.05$.

Table 6: \% inhibition concentration for $\mathrm{H}_{2} \mathrm{O}_{2}$ radical scavenging activity of Seed extracts of Carissa carandas

\begin{tabular}{|c|c|c|c|c|c|c|c|c|c|c|}
\hline \multirow{2}{*}{$\begin{array}{l}\text { Sl. } \\
\text { No }\end{array}$} & \multirow{2}{*}{$\begin{array}{l}\text { Conc. } \\
(\mu \mathrm{g} / \mathrm{m} \\
1)\end{array}$} & \multicolumn{9}{|c|}{ \%inhibition } \\
\hline & & $\begin{array}{l}\text { ascorbic } \\
\text { acid }\end{array}$ & methanol & ethanol & chloroform & acetone & water & $\begin{array}{l}\text { diethyl } \\
\text { ether }\end{array}$ & $\begin{array}{c}\text { petroleum } \\
\text { ether }\end{array}$ & $\begin{array}{l}\text { ethyl } \\
\text { acetate }\end{array}$ \\
\hline 1 & 10 & $10.79 \pm 0.20$ & $24.70 \pm 0.20$ & $45.75 \pm 0.20$ & $28.14 \pm 0.20$ & $10.53 \pm 0.20$ & $8.70 \pm 0.20$ & $12.82 \pm 0.12$ & $5.87 \pm 0.20$ & $7.49 \pm 0.20$ \\
\hline 2 & 20 & $27.47 \pm 0.20$ & $37.25 \pm 0.20$ & $60.39 \pm 0.12$ & $45.55 \pm 0.20$ & $18.62 \pm 0.20$ & $18.42 \pm 0.20$ & $28.34 \pm 0.20$ & $20.65 \pm 0.20$ & $10.73 \pm 0.20$ \\
\hline 3 & 40 & $36.47 \pm 0.47$ & $55.06 \pm 0.20$ & $70.11 \pm 0.31$ & $63.16 \pm 0.20$ & $30.57 \pm 0.20$ & $21.86 \pm 0.41$ & $33.20 \pm 0.20$ & $31.98 \pm 0.21$ & $25.44 \pm 0.12$ \\
\hline 4 & 80 & $53.36 \pm 0.59$ & $63.09 \pm 0.31$ & $91.10 \pm 0.20$ & $83.20 \pm 0.20$ & $46.22 \pm 0.31$ & $40.49 \pm 0.20$ & $46.15 \pm 0.70$ & $48.18 \pm 0.20$ & $38.80 \pm 0.31$ \\
\hline 5 & 160 & $54.5 \pm 0.45$ & $85.43 \pm 0.20$ & $92.11 \pm 0.20$ & $91.30 \pm 0.20$ & $74.49 \pm 0.21$ & $63.36 \pm 0.20$ & $47.71 \pm 0.31$ & $86.44 \pm 0.20$ & $46.97 \pm 0.20$ \\
\hline
\end{tabular}

*Data are mean of triplicate measurements \pm standard deviation. Each measurement were significantly different at $\mathrm{p}<0.05$.

Table 7: Reducing power of Fruit extracts of Carissa carandas L.

\begin{tabular}{|ccccccccccc|}
\hline $\begin{array}{c}\text { Sl. } \\
\text { No }\end{array} \begin{array}{c}\text { Conc. } \\
(\mu \mathrm{g} / \\
\mathrm{ml})\end{array}$ & & Ascorbic acid & methanol & ethanol & chloroform & acetone & water & $\begin{array}{c}\text { diethyl ether } \\
\text { petroleum } \\
\text { ether }\end{array}$ & $\begin{array}{c}\text { ethyl acetate } \\
\end{array}$ \\
\hline 1 & 10 & $0.454 \pm 0.002$ & $0.188 \pm 0.001$ & $0.181 \pm 0.002$ & $0.175 \pm 0.001$ & $0.163 \pm 0.002$ & $0.141 \pm 0.001$ & $0.130 \pm 0.001$ & $0.107 \pm 0.002$ & $0.128 \pm 0.001$ \\
\hline 2 & 20 & $0.646 \pm 0.001$ & $0.294 \pm 0.001$ & $0.382 \pm 0.002$ & $0.288 \pm 0.001$ & $0.412 \pm 0.001$ & $0.504 \pm 0.001$ & $0.350 \pm 0.001$ & $0.437 \pm 0.002$ & $0.267 \pm 0.001$ \\
\hline 3 & 40 & $0.734 \pm 0.002$ & $0.425 \pm 0.001$ & $0.518 \pm 0.001$ & $0.508 \pm 0.001$ & $0.616 \pm 0.001$ & $0.713 \pm 0.001$ & $0.466 \pm 0.001$ & $0.556 \pm 0.002$ & $0.520 \pm 0.002$ \\
\hline 4 & 80 & $0.816 \pm 0.001$ & $0.624 \pm 0.001$ & $0.740 \pm 0.001$ & $0.830 \pm 0.001$ & $0.902 \pm 0.001$ & $0.818 \pm 0.001$ & $0.769 \pm 0.001$ & $0.889 \pm 0.002$ & $0.908 \pm 0.002$ \\
\hline 5 & 160 & $1.098 \pm 0.001$ & $1.915 \pm 0.002$ & $1.806 \pm 0.001$ & $1.624 \pm 0.001$ & $1.514 \pm 0.001$ & $1.332 \pm 0.001$ & $1.315 \pm 0.002$ & $1.258 \pm 0.001$ & $1.303 \pm 0.002$ \\
\hline
\end{tabular}

${ }^{*}$ Data are mean of triplicate measurements \pm standard deviation. Each measurement were significantly different at $\mathrm{p}<0.05$. 


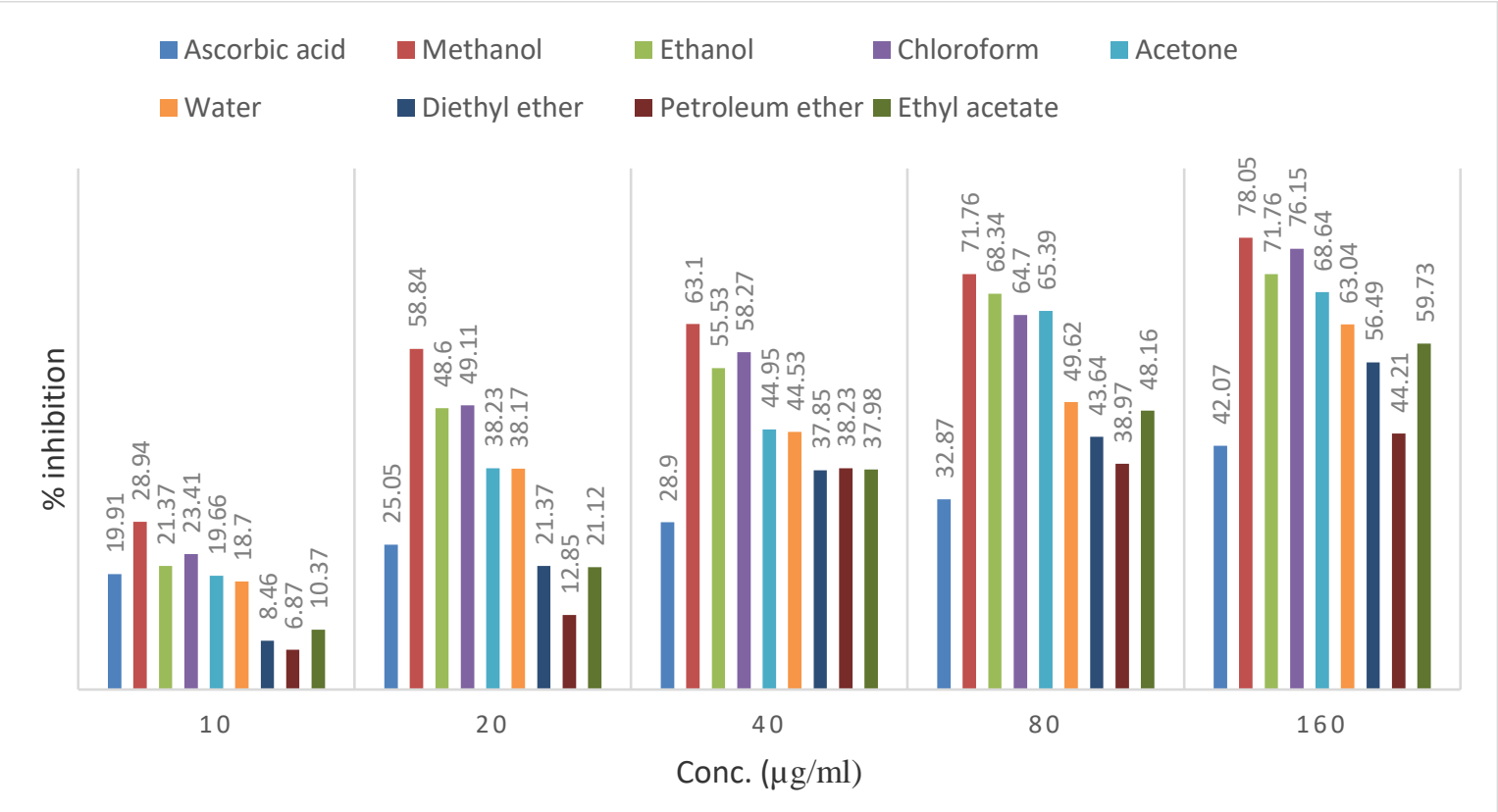

Figure 4: DPPH scavenging activity of Seed extracts of Carissa carandas

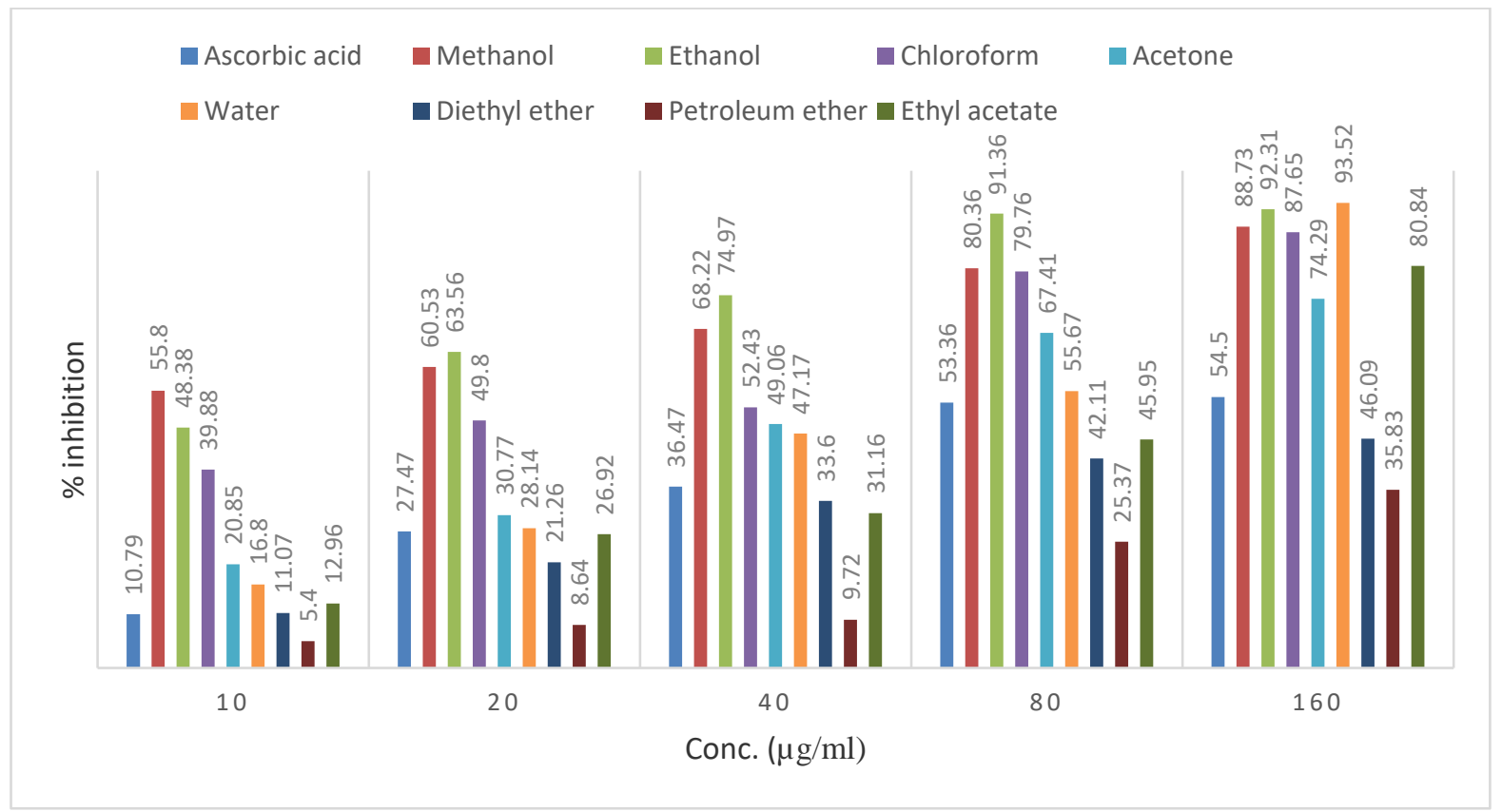

Figure 5: $\mathrm{H}_{2} \mathrm{O}_{2}$ scavenging activity of Fruit extracts of Carissa carandas

Table 8: Reducing power of Leaf extracts of Carissa carandas

\begin{tabular}{|ccccccccccc|}
\hline $\begin{array}{c}\text { Sl. } \\
\text { No }\end{array} \begin{array}{c}\text { Conc. } \\
(\mu \mathrm{g} / \\
\mathrm{ml})\end{array}$ & & Ascorbic acid & methanol & ethanol & chloroform & acetone & water & diethyl ether & $\begin{array}{c}\text { petroleum } \\
\text { ether }\end{array}$ & ethyl acetate \\
\hline 1 & 10 & $0.454 \pm 0.002$ & $0.167 \pm 0.002$ & $0.128 \pm 0.002$ & $0.162 \pm 0.001$ & $0.105 \pm 0.001$ & $0.096 \pm 0.002$ & $0.086 \pm 0.002$ & $0.085 \pm 0.001$ & $0.092 \pm 0.001$ \\
\hline 2 & 20 & $0.646 \pm 0.001$ & $0.252 \pm 0.001$ & $0.426 \pm 0.003$ & $0.313 \pm 0.001$ & $0.214 \pm 0.001$ & $0.357 \pm 0.002$ & $0.244 \pm 0.001$ & $0.396 \pm 0.002$ & $0.108 \pm 0.002$ \\
\hline 3 & 40 & $0.734 \pm 0.002$ & $0.394 \pm 0.001$ & $0.552 \pm 0.001$ & $0.405 \pm 0.001$ & $0.315 \pm 0.002$ & $0.473 \pm 0.002$ & $0.350 \pm 0.002$ & $0.567 \pm 0.001$ & $0.568 \pm 0.001$ \\
\hline 4 & 80 & $0.816 \pm 0.001$ & $0.820 \pm 0.001$ & $0.915 \pm 0.002$ & $0.620 \pm 0.001$ & $0.728 \pm 0.001$ & $0.916 \pm 0.002$ & $0.619 \pm 0.002$ & $0.915 \pm 0.004$ & $0.796 \pm 0.001$ \\
\hline 5 & 160 & $1.098 \pm 0.001$ & $1.574 \pm 0.001$ & $1.497 \pm 0.001$ & $1.572 \pm 0.001$ & $1.402 \pm 0.002$ & $1.357 \pm 0.001$ & $1.241 \pm 0.001$ & $1.213 \pm 0.002$ & $1.341 \pm 0.001$ \\
\hline
\end{tabular}

${ }^{*}$ Data are mean of triplicate measurements \pm standard deviation. Each measurement were significantly different at $\mathrm{p}<0.05$. 
Table 9: Reducing power of Seed extracts of Carissa carandas

\begin{tabular}{|ccccccccccc|}
\hline $\begin{array}{c}\text { Sl. } \\
\text { No }\end{array} \begin{array}{c}\text { Conc. } \\
(\mu \mathrm{g} / \\
\mathrm{ml})\end{array}$ & & Ascorbic acid & methanol & ethanol & chloroform & acetone & water & $\begin{array}{c}\text { diethyl ether } \\
\text { petroleum } \\
\text { ether }\end{array}$ & $\begin{array}{c}\text { ethyl acetate } \\
\end{array}$ \\
\hline 1 & 10 & $0.454 \pm 0.002$ & $0.135 \pm 0.001$ & $0.141 \pm 0.001$ & $0.110 \pm 0.001$ & $0.113 \pm 0.001$ & $0.095 \pm 0.001$ & $0.090 \pm 0.001$ & $0.085 \pm 0.001$ & $0.073 \pm 0.002$ \\
\hline 2 & 20 & $0.646 \pm 0.001$ & $0.245 \pm 0.001$ & $0.244 \pm 0.001$ & $0.423 \pm 0.002$ & $0.324 \pm 0.001$ & $0.313 \pm 0.001$ & $0.293 \pm 0.001$ & $0.364 \pm 0.001$ & $0.414 \pm 0.002$ \\
\hline 3 & 40 & $0.734 \pm 0.002$ & $0.667 \pm 0.008$ & $0.548 \pm 0.001$ & $0.809 \pm 0.001$ & $0.720 \pm 0.002$ & $0.708 \pm 0.001$ & $0.585 \pm 0.001$ & $0.627 \pm 0.001$ & $0.704 \pm 0.002$ \\
\hline 4 & 80 & $0.816 \pm 0.001$ & $1.207 \pm 0.002$ & $1.194 \pm 0.001$ & $0.913 \pm 0.001$ & $1.092 \pm 0.001$ & $0.812 \pm 0.002$ & $0.943 \pm 0.002$ & $0.887 \pm 0.002$ & $0.716 \pm 0.002$ \\
\hline 5 & 160 & $1.098 \pm 0.001$ & $1.218 \pm 0.002$ & $1.265 \pm 0.001$ & $1.197 \pm 0.001$ & $1.205 \pm 0.002$ & $1.171 \pm 0.001$ & $1.152 \pm 0.001$ & $1.125 \pm 0.002$ & $1.113 \pm 0.002$ \\
\hline
\end{tabular}

${ }^{*}$ Data are mean of triplicate measurements \pm standard deviation. Each measurement were significantly different at $\mathrm{p}<0.05$.

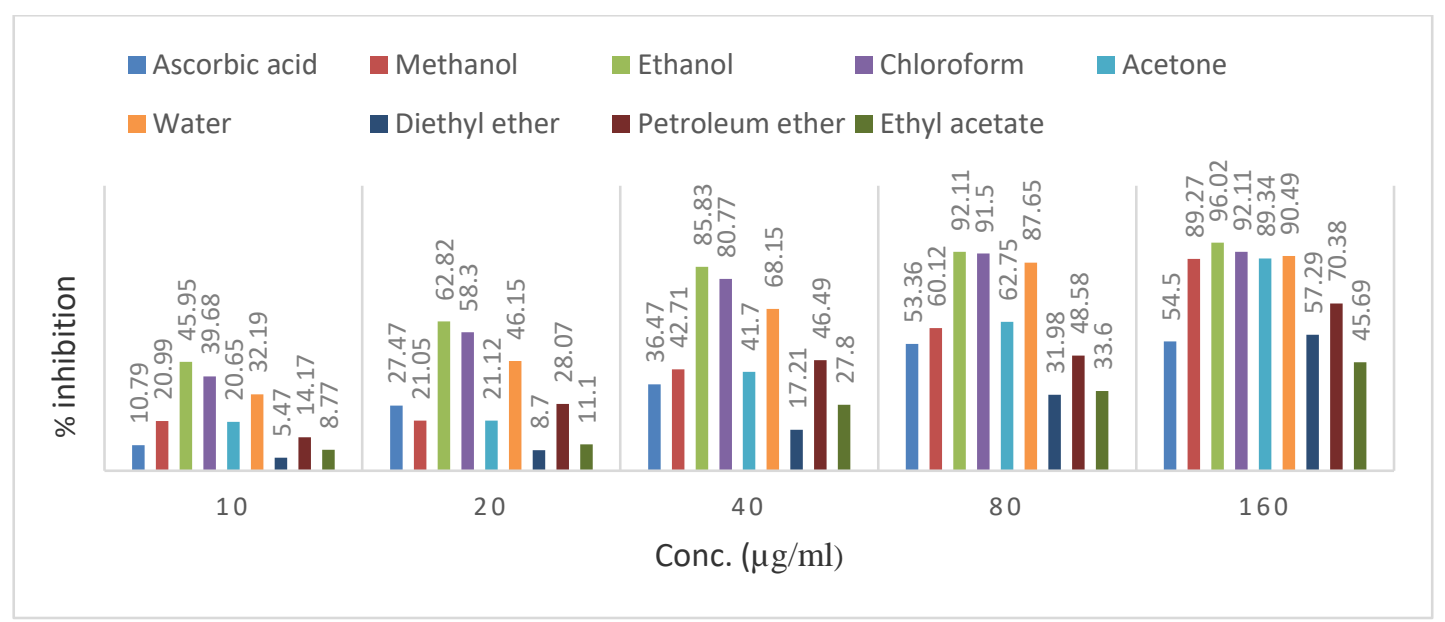

Figure 6: $\mathrm{H}_{2} \mathrm{O}_{2}$ scavenging activity of Leaf extracts of Carissa carandas

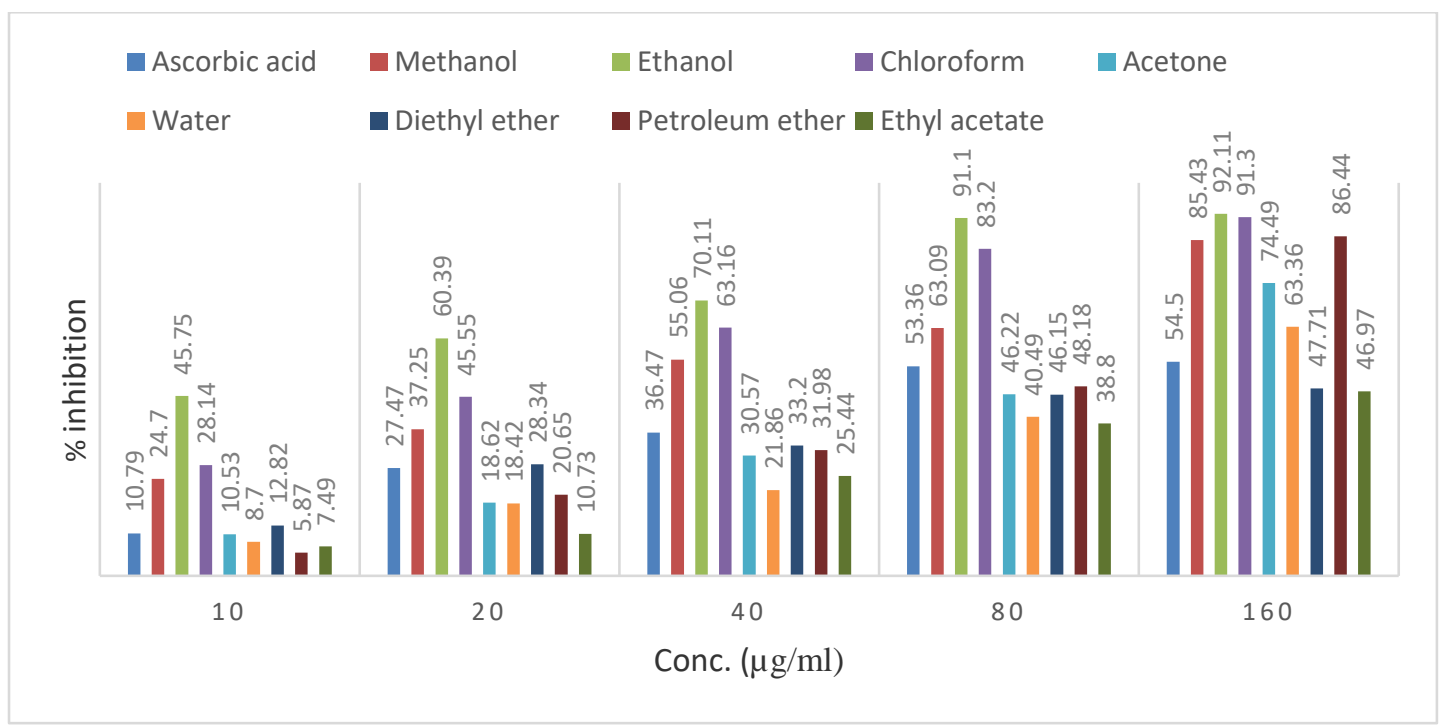

Figure 7: $\mathrm{H}_{2} \mathrm{O}_{2}$ scavenging activity of Seed extracts of Carissa carandas 
Dipanjali Saikia, P.J. Handique. Int J Sci Res Sci Technol.March-April-2019; 6(2) :13-25

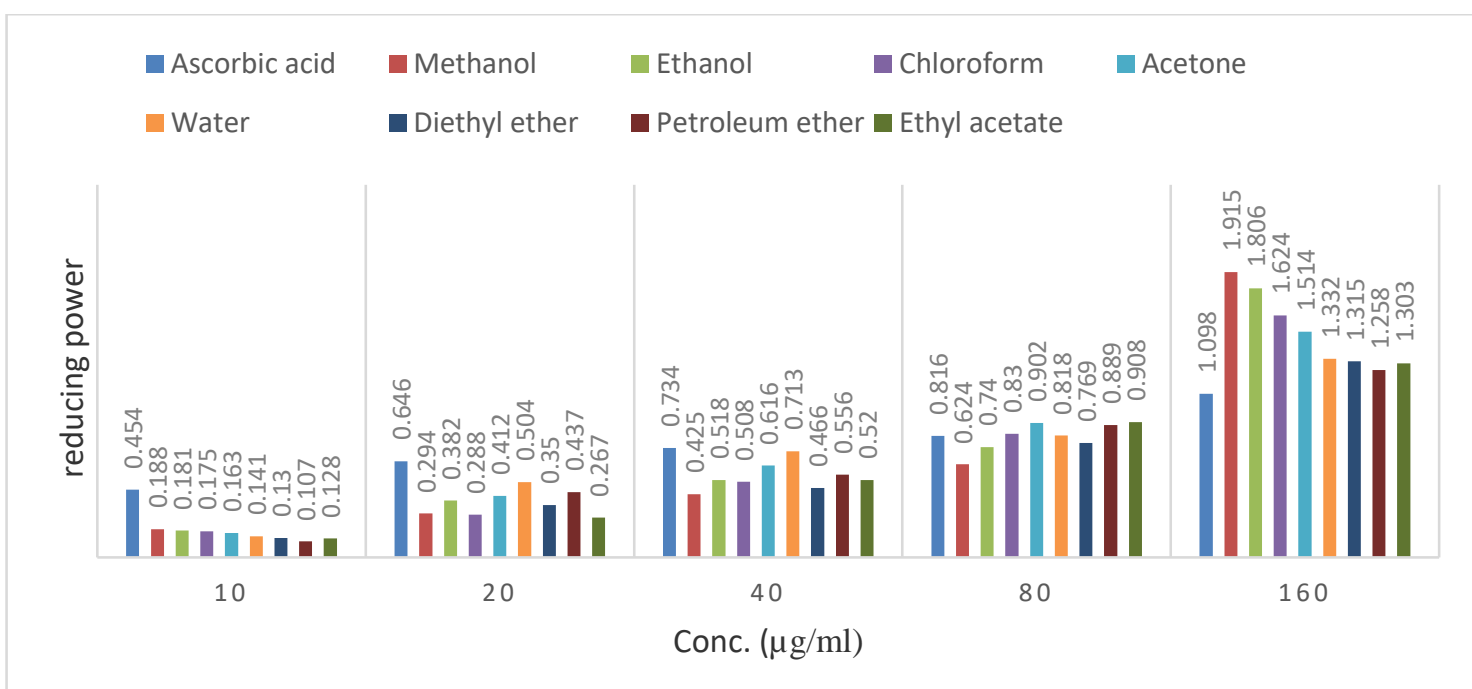

Figure 8: Reducing power of Fruit extracts of Carissa carandas

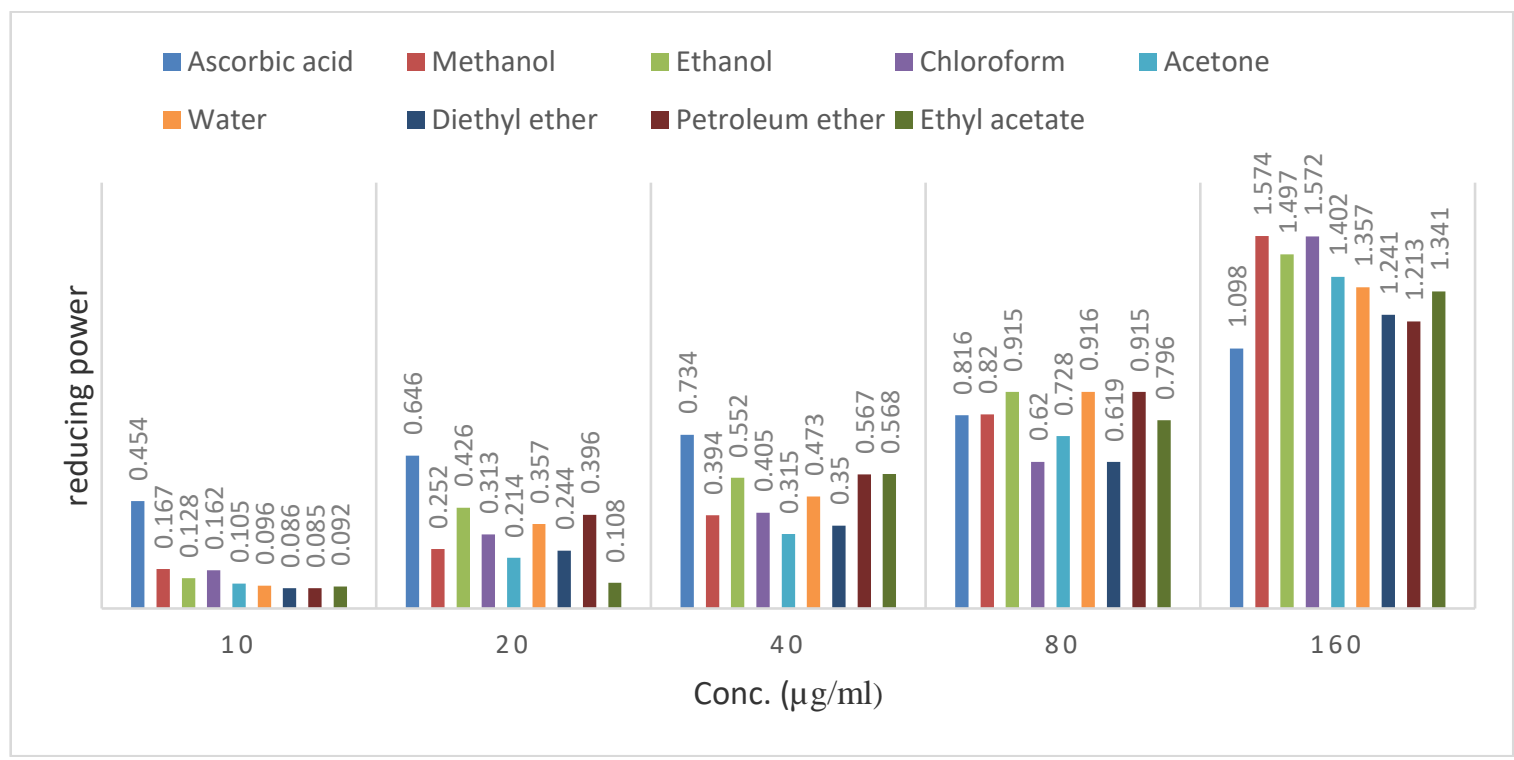

Figure 9: Reducing power of Leaf extracts of Carissa carandas

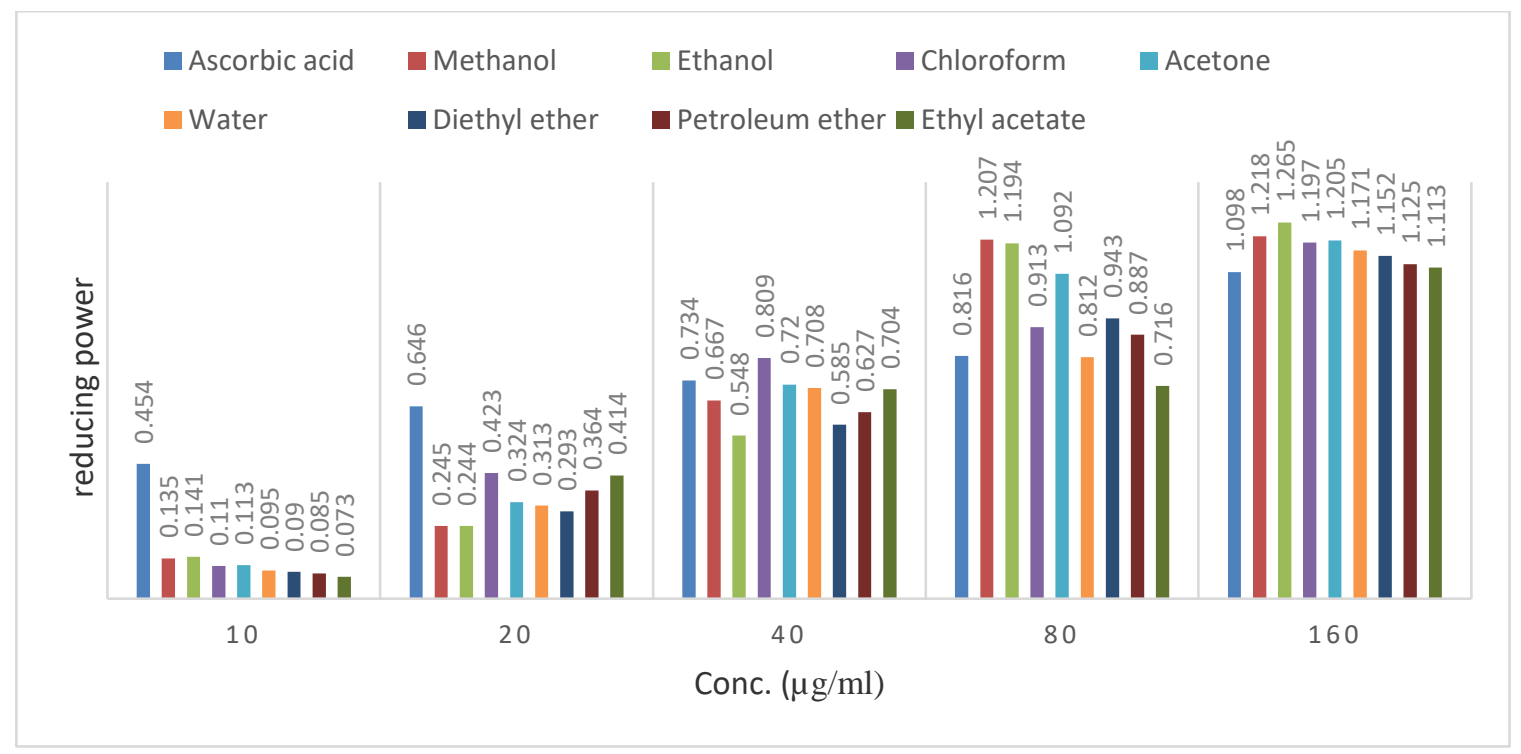

Figure 10: Reducing power of Seed extracts of Carissa carandas 
The results revealed that $\mathrm{DPPH}$ and $\mathrm{H}_{2} \mathrm{O}_{2}$ radical scavenging activity was recorded in terms of \% inhibition as shown in the tables and figures. It was observed that extract with the highest effective DPPH radical scavenging activity and reducing power was the methanol extract of $C$. carandas fruit while ethanol extract of fruit showed the highest effective $\mathrm{H}_{2} \mathrm{O}_{2}$ radical scavenging activity. Petroleum ether, ethyl acetate and diethyl ether showed lowest radical scavenging activity and reducing power assay. The results were compared to the standard (LAscorbic acid). Higher \% inhibition represented better antioxidant potential of the extract. The extracts were investigated for their reducing capabilities by using potassium ferricyanide reduction method. The reducing ability may serve as a significant indicator of potential antioxidant activity [18]. The fruit, leaf and seed extracts increased in reducing powers with increasing concentration. The fruit and leaf extracts exhibited highest reducing ability than the seed extracts. The methanol extracts of fruit and leaf showed the highest activity and petroleum ether showed lowest while ethanol extract of seed showed the highest and ethyl acetate showed lowest reducing activity. Table 7-9 depicted the reducing power of the extracts.

The fruit and leaf extracts had significantly higher antioxidant properties than seed. This result was correlated with reducing power assay where fruit and leaf extracts were also found more significant than seed extracts. The antioxidant potential was determined to be in the following order: Fruit $>$ Leaf $>$ Seed extracts. The studies suggest that the fruits, leaves and seeds extracts of $C$. carandas possesses potent in vitro antioxidant activity and act as an effective free radical scavenger. Methanol extracts of $C$. carandas show exceeding good results to extract TPC and TFC and its antioxidant activity. Further study on the same can be of immense value as therapeutic drugs and thus protecting our body from various diseases. Earlier work on various other plant species was also in conformity with the present findings [1], [2], [18], [19], [20], [21], [23].In the present study, the fruit and leaf extracts of $C$. carandas showed significantly higher antioxidant properties than seed. The result was correlated with reducing power assay where fruit and leaf extracts were found more significant than seed extracts. The studies suggested that the fruits, leaves and seeds extracts of $C$. carandas possesses antioxidant ability and act as an effective free radical scavenger.

\section{IV.CONCLUSION}

From the present study, it can be concluded that solvent extracts of various parts of Carissa carandas exhibited potent free radical scavenging properties. The fruit extracts of $C$. carandas exhibited a higher free radical scavenging ability. The inhibition percentage of fruit methanol extract showed highest radical scavenging activity gradually increasing from $28.37 \%$ to $91.22 \%$ at $10 \mu \mathrm{g} / \mathrm{ml}$ to $160 \mu \mathrm{g} / \mathrm{ml}$ concentration of the extracts. Methanol and ethanol extract of fruits showed $50 \%$ and above inhibition at $40 \mu \mathrm{g} / \mathrm{ml}$ concentration. The leaf extracts exhibited radical scavenging activity from $28.37 \%$ to $80.79 \%$ at $10 \mu \mathrm{g} / \mathrm{ml}-160 \mu \mathrm{g} / \mathrm{ml}$.

\section{ACKNOWLEDGEMENT}

The Department of Biotechnology (DBT), Government of India, New Delhi is duly acknowledged for laboratory facilities for the work. We also acknowledge the Head, Department of Biotechnology, Gauhati University, Assam, India for logistic help and encouragement during the work.

\section{REFERENCES}

[1] B. Halliwell, M.A. Murcia, S. Chirico and O.I. Aruoma (1955). Free radicals and antioxidants in 
food and in vivo: what they do and how they work. Critical Reviews in Food Science and Nutrition; 35: 7-20.

[2] L.J. Machlin and A. Bendich (1987). Free radical tissue damages: protective role of antioxidant nutrients. FASEBJ; 1:441-445.

[3] M. Dusinska, J. Lietava, B. Olmedilla, K. Raslova, S. Southon, A.R. Collins, T.K. Basu, N.J. Temple and M.L. Garg (1999). Indicators of Antioxidative stress in Antioxidants and Human Health; New York, USA: CAB International; 411- 422.

[4] Dhan Prakash, Garima Upadhyay and P. Pushpangadan (2011). Antioxidant Potential of Some Under-Utilized Fruits.Indo-Global Journal of Pharmaceutical Sciences; 1: 25-32.

[5] P.J. Handique (2009). Medicinal Plants of North East India: Status Diversity Conservation Cultivation \& Trade. Year: 2009, International Book Distributors, Dehradun; ISBN: 9788170893530 / 8170893534.

[6] Berhane Kidane, L.J.G. van der Maesen, Tinde van Andel, Zemede Asfaw and M.S.M. Sosef (2014). Ethnobotany of Wild and Semi-Wild Edible Fruit Species used by Maale and Ari Ethnic Communities in Southern Ethiopia. Ethnobotany Research \& Applications 12:455471.

[7] K.R. Kirtikar and B.D. Basu (2005). Indian Medicinal Plant, Vol I, 2nd Ed, Dehradun. International Book Distributors; 1546 -1548.

[8] D.M.A. Jayaweera (1981). Medical Plants used in Ceylon, Colombo. National Science Council of Srilanka; 42-49.

[9] V.H Bhaskar and N. Balakrishnan (2009). Analgesic, anti-inflammatory and antipyretic activities of Pergularia deamia and Carissa Carandas. DARU Journal of Pharmaceutical Sciences; 17(3):168-174.

[10] V.H. Bhaskar and N. Balakrishnan (2009). Karaunda (Carissa carandas Linn.)- As a phytomedicine: A review. Kongposh publications; 95-100.

[11] B.N. Dhawan and G.K. Patnaik (1985). Investigation on some new cardio-active glycosides. Indian drugs; 22 (6):285-290.

[12] R.S.L. Taylor, J.B. Hudson, N.P. Manandhar and G.H.N. Tower (1996). Antiviral Activities of Medicinal Plant of Southern Nepal. Journal of Ethno pharmacology; 53(2):97-104.

[13] Rajasekaran, V. Jeyasudh, B. Kalpana and B. Jayakar (1999). Preliminary Phytochemical and antipyretic evaluation of Carissa carandas L.; Indian J. of natural Prod., 15 (1): 27-29.

[14] M. Blois (1958). Antioxidant determinations by the use of a stable free radical. Nature.181:11991200. doi: 10.1038/1811199a0.

[15] R.J. Ruch, S.J. Cheng and J.E. Klaunig (1989). Prevention of cytotoxicity and inhibition of intracellular communication by antioxidant catechins isolated from Chinese green tea. Carcinogenesis; 10: 1003-1008.

[16] W. Yu, Y. Zhao and B. Shu (2004). The radical scavenging activities of radix puerariae isoflavonoids: A chemiluminescence study. Food Chem. 86:525-529. doi: 10.1016/j.foodchem.2003.08.037.

[17] A. Yildrin, M. Okay and V. Bilaloglu (2001). The antioxidant activity of leaves of Cydonia vulgaris. Turkish Journal of Medical Science;31:23-27.

[18] S. Meir, J. Kanner, B. Akiri and S.P. Hadas (1995). Determination and involvement of aqueous reducing compounds in oxidative defense systems of various senescing leaves. J. Agric. Food Chem.; 43: 1831-181.

[19] Aman Deep Kaur, Parminder Nain and Jaspreet Nain (2012). In vitro Antimicrobial and Antioxidant Activity of Gingko biloba Bark Extract. International Research Journal of Pharmacy. 3(6):2230-8407.

[20] D. Prakash, B.N. Singh and G. Upadhyay (2007). Antioxidant and free radical scavenging 
activities of phenols from onion (Allium cepa);

Food Chemistry 102: 1389-1393.

[21] Farah Aslam, Nasir Rasool, Md. Riaz, Md. Zubair, Komal Rizwan, Mazhar Abbas, Tanveer Hussain Bukhari and Iftikhar Hussain Bukhari (2011). Antioxidant, haemolytic activities and GC-MS profiling of Carissa carandas roots. International Journal of Phytomedicine; 3:567578.

[22] J. Kubola, S. Siriamornpun and N. Meeso (2011).Phytochemicals, vitamin $C$ and sugar content of Thai wild fruits; Food Chem. 126:97298.

[23] S.I. Mamun, N. Shaheen, A. BasakTukun and Md. Mohiduzzaman (2012). Hydrophilic Antioxidant Capacities and Total Phenol Content of Seasonal Fruits of Bangladesh. Mal J Nutr.; 18(3):355-362.

\section{Cite this article as :}

Dipanjali Saikia, P.J. Handique, "Evaluation of in vitro antioxidant potential of Carissa carandas genotype found in NE India", International Journal of Scientific Research in Science and Technology (IJSRST), Online ISSN : 2395-602X, Print ISSN : 2395-6011, Volume 6 Issue 2, pp. 13-25, March-April 2019. Available at doi : https://doi.org/10.32628/IJSRST19621 Journal URL :http://ijsrst.com/IJSRST19621 